\title{
Catheter inside the right heart for 22 years: to intervene or not to intervene?
}

\author{
Tolga Çimen, Mehmet Doğan, Ahmet Akyel, Ekrem Yeter \\ Dışkapı Yıldırım Beyazıt Education and Research Hospital, Ankara, Turkey
}

Postep Kardiol Inter 2015; 11, 1 (39): 62-63

DOI: $10.5114 /$ pwki.2015.49189

\begin{abstract}
A bstract
Treatment of a central venous catheter emboli that has been asymptomatic for a number of years is controversial. A 56-yearold male patient who had an operation for sinus Valsalva aneurism rupture 22 years ago was referred to cardiology department for routine control. He had a mass inside the right heart on echocardiographic examination, and computed tomography revealed that this mass was an embolic piece of catheter. Catheters that have stayed inside the heart for a long time are removed due to the risk of distal embolisation and endocarditis, but the risk of removal is not known. Non-invasive follow-up of asymptomatic patients is often preferred because of the stabilisation of the embolised catheter due to endothelisation and the risk of complications during removal. Treatment of patients with catheter-piece emboli who are asymptomatic should be individualised, taking into account the risk of thrombosis, arrhythmia, and infection.
\end{abstract}

Key words: central venous catheter, catheter embolus.

\section{Introduction}

There are scarce case reports about leaving foreign objects inside the body during open heart surgery or related invasive procedures. Central venous catheterisation is used as an intravenous line; it is necessary for haemo-

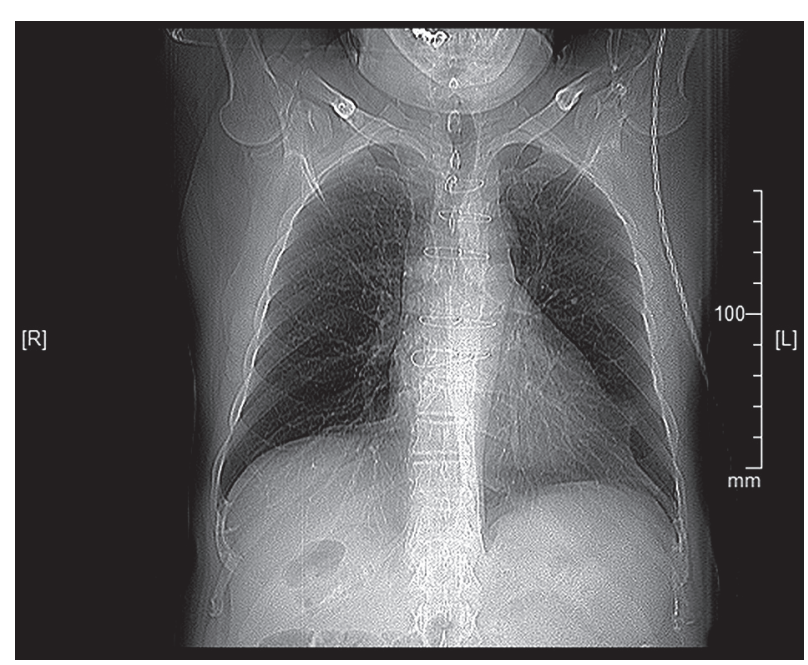

Figure 1. No catheter was observed on the PA chest radiography dialysis and for the measurement of the right heart pressures, so it is essential during these kinds of surgeries.

We present the case of a man who had an operation for sinus valsalva aneurysm rupture 22 years ago and had an asymptomatic catheter fragment in the right heart.

\section{Case report}

A 56-year-old male patient who had an operation for sinus valsalva aneurism rupture 22 years previously was referred to the cardiology department for routine control. He had no complaint. He was unable to find his surgical report. In his medical history he had hypertension and aortic operation. On physical examination he had soft early diastolic murmur at left sternal border. The ECG was at sinus rhythm. On transthorasic examination he had ascending aortic dilatation $(5 \mathrm{~cm})$ and minimal aortic regurgitation. In addition he had a hyperechogenic mass resembling a pacemaker electrode extending from the right atrium to the right ventricle. This piece was not radio-opaque on the chest $\mathrm{X}$-ray (Figure 1). Cardiac computed tomography (CT) angiogram revealed that this piece was a catheter extending from the right ventricle to the right atrial appendage (Figures 2-3). The catheter

Corresponding author:

Tolga Çimen MD, Dışkapı Yıldırım Beyazıt Education and Research Hospital, Altındağ, 06590 Ankara, Turkey, phone: +905053273065, e-mail: drtolgacim@hotmail.com

Received: 25.08.2014, accepted: 8.01.2015. 


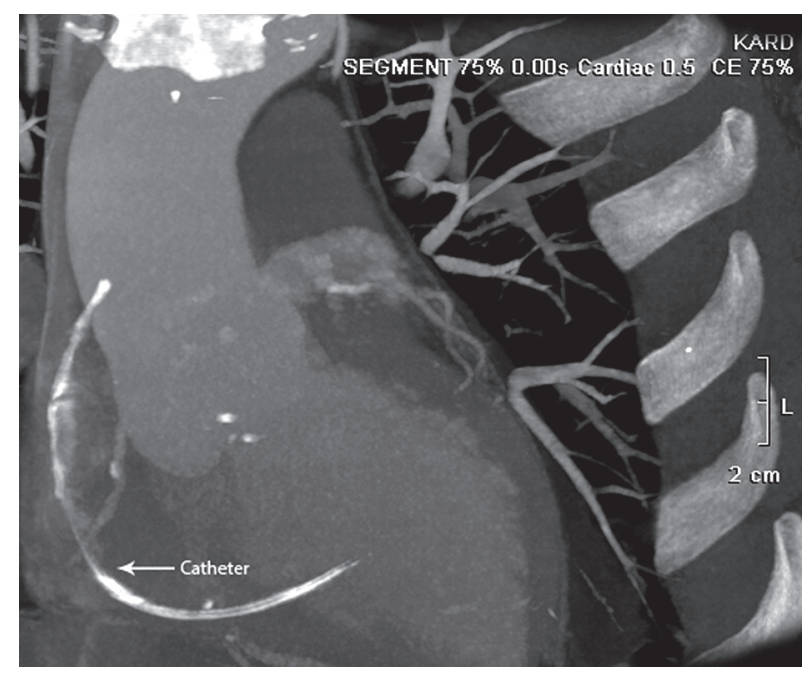

Figure 2. Placement of the catheter on a two-dimensional computed tomography image

fragment was approximately $14 \mathrm{~cm}$ long and had a diameter of $3.3 \mathrm{~mm}$. He had no arrhythmia on 24-hour Holter monitoring. The patient was asymptomatic and decided to be followed noninvasively.

\section{Discussion}

Embolisation of central venous catheters occurs rarely, but they can cause serious complications such as fatal ventricular arrhythmias, septic embolisations, endocarditis, and right heart failure secondary to repetitive thromboembolism [1]. Pinch-off syndrome, described as breakage of the catheter due to compression of the central venous catheter at the infraclavicular area, is known to be the most common reason [2]. Besides iatrogenic destruction of the catheters during exchange or removal, disconnection of the cannula from the fitting side, and the rupture of the catheter are the other reasons. Emboli usually occurs to the vena cava superior or peripheral veins (15.4\%), right atrium (27.6\%), right ventricle (22\%), or pulmonary arteries (35\%) [1]. Most of them can be removed percutaneously and surgery is necessary only in rare cases $[3,4]$. Some authors recommend the removal of the catheters even in asymptomatic patients due to the risk of distal embolisation and endocarditis; there are also cases that have not been removed [5-7]. Our patient was asymptomatic after 22 years, so we thought that the catheter would be stabilised due to endothelialisation and we did not want take the risk of complications during removal.

\section{Conclusions}

In the case of the early diagnosis of the embolisation of the fragmented catheters, percutaneous removal could be the preferred way of treatment; however, asymptomatic patients diagnosed after a long time can be

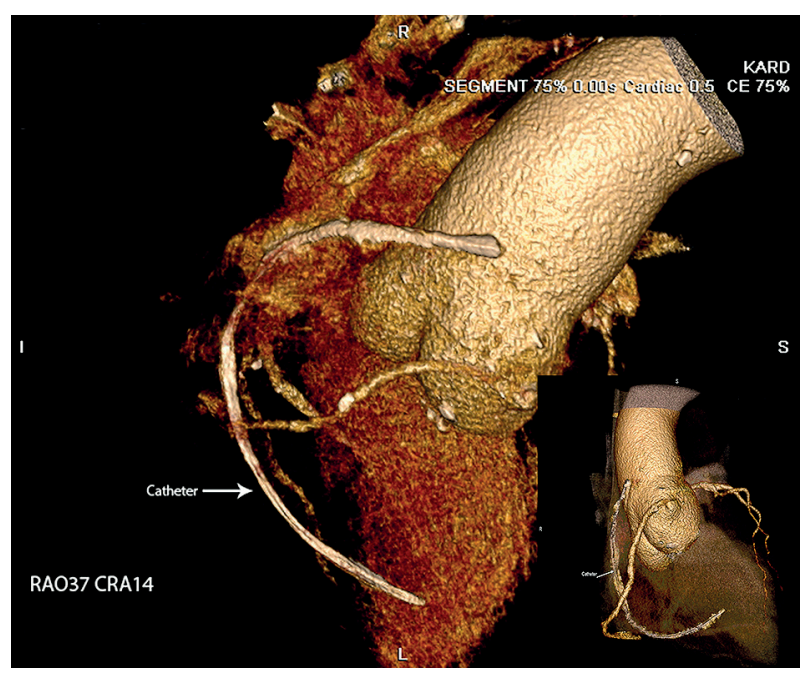

Figure 3. Placement of the catheter on the right heart on three-dimensional computed tomography angiography

followed non-invasively. Treatment of the patients should be individualised, taking into account the risk of thrombosis, arrhythmia, and infection.

\section{Conflict of interest}

The authors declare no conflict of interest.

\section{References}

1. Surov A, Wienke A, Carter JM, et al. Intravascular embolization of venous catheter: causes, clinical signs, and management: a systematic review. JPEN J Parenter Enteral Nutr 2009; 33: 677-85.

2. Aitken DR, Minton JP. The "pinch-off sign": a warning of impending problems with permanent subclavian catheters. Am J Surg 1984; 148: 633-6.

3. Onal B, Coskun B, Karabulut R, et al. Interventional radiological retrieval of embolized vascular access device fragments. Diagn Interv Radiol 2012; 18: 87-91.

4. Nair HC, Banakal S, Parachuri VR, et al. Entrapped central venous catheter after mitral valve replacement and its surgical retrieval. Interact Cardiovasc Thorac Surg 2012; 15: 566-7.

5. Toda R, Yuda T, Nishida T, et al. Retrieval of intravascular catheter fragment remaining for 15 years: a case report. Nihon Kyobu Geka Gakkai Zasshi 1997; 45: 51-4.

6. Thanigaraj S, Panneerselvam A, Yanos J. Retrieval of an IV catheter fragment from the pulmonary artery 11 years after embolization. Chest 2000; 117: 1209-11.

7. El-Heis S, Ormerod JO, Chandrasekaran B, et al. A retained pulmonary artery catheter fragment incidentally found lodged in the right heart 16 years after its insertion. BMJ Case Rep 2013 Mar 26; 2013. pii: bcr2013008640. doi: 10.1136/bcr-2013-008640. 